\title{
Modulation of the Homocysteine-Betaine Relationship by Methylenetetrahydrofolate Reductase 677 C->T Genotypes and B-Vitamin Status in a Large-Scale Epidemiological Study
}

\author{
Pål I. Holm, Steinar Hustad, Per Magne Ueland, Stein Emil Vollset, Tom Grotmol, and Jørn Schneede \\ Hormone Laboratory (P.I.H., S.H.), Haukeland University Hospital, Bergen 5021, Norway; LOCUS for Homocysteine and \\ Related Vitamins (P.M.U., J.S.), Institute of Medicine, University of Bergen, 5021 Bergen, Norway; LOCUS for \\ Homocysteine and Related Vitamins (S.E.V.), Department of Public Health and Primary Health Care, University of Bergen, \\ 5021 Bergen, Norway; Cancer Registry of Norway (T.G.), Institute of Population-Based Cancer Research, Montebello, 0310 \\ Oslo, Norway
}

\begin{abstract}
Context: Betaine is formed from the essential nutrient choline or is supplied from the diet. It serves as a substrate in the betaine-homocysteine methyltransferase reaction and thereby provides methyl groups for the homocysteine-methionine cycle, which is regulated by enzymes dependent on folate, vitamin B12, riboflavin (vitamin B2), or vitamin B6.
\end{abstract}

Objective: We investigated how betaine affected total homocysteine (tHcy) concentration within the frame of variable B-vitamin status and according to the methylenetetrahydrofolate reductase (MTHFR) $677 \mathrm{C}->\mathrm{T}$ genotype.

Design/Setting/Patients: This is a population-based study with a cross-sectional design. It includes 10,601 healthy men and women aged 50-64 yr.
Outcome Measures: Plasma samples were analyzed for tHcy, betaine, choline, dimethylglycine, riboflavin, and vitamin B6, whereas folate and vitamin B12 were analyzed in serum.

Results: Betaine was a strong determinant of plasma tHcy in subjects with low serum folate and the MTHFR TT genotype. The association was further strengthened at low levels in the circulation of the other Bvitamins (B2, B6, and B12). Thus, in subjects with the combination of serum folate in the lowest quartile, low vitamin B2, B6, and B12 status, and the MTHFR TT genotype, the difference in tHcy (mean, 95\% confidence interval) across extreme plasma betaine quartiles was 8.8 (1.316.2) $\mu \mathrm{mol} /$ liter.

Conclusion: Betaine may thus be an important one-carbon source, particularly in MTHFR 677 TT subjects with inadequate B-vitamin status. (J Clin Endocrinol Metab 92: 1535-1541, 2007)
$\mathrm{H}^{\mathrm{o}}$ OMOCYSTEINE (Hcy) is a sulfhydryl amino acid, which is generated from methionine in transmethylation reactions. The plasma concentration of reduced and oxidized forms of Hcy, collectively termed total Hcy (tHcy), is affected by lifestyle and nutritional factors (1). Moderately elevated levels of tHcy are related to an increased risk of cardiovascular disease, impaired cognition, and other conditions $(2,3)$. Severe hyperhomocysteinemia is found in patients with homocystinuria, who have a high risk of occlusive vascular disease (4).

Betaine, at doses up to $9 \mathrm{~g} / \mathrm{d}$, has for years been used as a tHcy-lowering agent in patients with homocystinuria (4). It also reduces fasting tHcy (5-10) and reduces the increase in tHcy induced by high doses of methionine, i.e. postmethionine load (PML) tHcy in healthy subjects $(7,8)$. We recently demonstrated that plasma betaine is a strong predictor

First Published Online February 6, 2007

Abbreviations: BHMT, Betaine-Hcy methyltransferase; DMG, dimethylglycine; GAM, generalized additive model; Hcy, homocysteine; MS, methionine synthase; 5-MTHF, 5-methyltetrahydrofolate; MTHFR, methylenetetrahydrofolate reductase; PLP, pyridoxal 5'-phosphate; PML, postmethionine load; tHcy, total Hcy.

JCEM is published monthly by The Endocrine Society (http://www. endo-society.org), the foremost professional society serving the endocrine community. of PML tHcy (11). Betaine was a weaker predictor of fasting tHcy, but the association was strengthened under conditions of low serum folate (11), suggesting that betaine is an alternative source of one-carbon units in folate-depleted subjects (12). Betaine provides one-carbon units by serving as a substrate for betaine-Hcy methyltransferase (BHMT), which catalyzes the remethylation of Hcy to methionine in the liver and kidney (13).

In most studies of healthy subjects, folate status is a more powerful predictor of plasma tHcy than vitamin B12, but overt B12 deficiency is associated with severe hyperhomocysteinemia (1). Vitamin B6 has minor (14) or no (15) effect on fasting tHcy, but may exert an effect on PML tHcy (16). Recent studies have added riboflavin (vitamin B2) to the spectrum of B-vitamins affecting the tHcy concentration (17). The relationship between B-vitamins and plasma concentration of tHcy is probably explained by their roles as substrates or cofactors for enzymes involved in Hcy remethylation or transsulfuration (18). Methylenetetrahydrofolate reductase (MTHFR) catalyzes the formation of 5-methyltetrahydrofolate (5-MTHF), which is the prevailing folate form in plasma (19) and the form involved in the conversion of Hcy to methionine (20). The homozygous TT genotype of the common MTHFR 677 C-> T polymorphism, which has a prevalence of approximately $10 \%$ in most Caucasian populations (21), is 
associated with impaired catalytic properties of the enzyme $(22,23)$, and is an important genetic determinant of plasma tHcy, particularly under conditions of low folate (24) or riboflavin (17) status.

Plasma tHcy is a responsive indicator of B-vitamin and MTHFR status. This is explained by metabolic reactions dependent on folate, vitamin B12, riboflavin, or vitamin B6, which converge on Hcy. In this study we used plasma tHcy as a probe to investigate how betaine affects one-carbon metabolism within the frame of variable B-vitamin status. We investigated a large population of 10,601 subjects. The study had sufficient statistical power to obtain novel data on the influence of betaine on one-carbon metabolism, with emphasis on the effect modification by B-vitamin status and the MTHFR $677 \mathrm{C}->\mathrm{T}$ polymorphism.

\section{Subjects and Methods \\ Subjects and protocol}

A total of 10,601 samples from subjects enrolled in the Norwegian Colorectal Cancer Prevention (NORCCAP) study were analyzed. NORCCAP is a prospective randomized study investigating sigmoidoscopy combined with fecal occult blood testing as screening modalities for colorectal cancer in a middle aged (range, 50-64 yr) population of both genders (25). Inclusion in the study took place from 1999-2001 at three hospitals in the city of Oslo and in Telemark County in southern Norway. A number of lifestyle variables were recorded, and blood samples were collected (26). The study was approved by the Regional Ethics Committee, and The Data Inspectorate approved the study protocol. Written informed consent was obtained from all participants.

\section{Blood collection and biochemical analysis}

At inclusion, blood samples were collected into EDTA Vacutainer tubes and tubes without additive. Serum was allowed to clot for $1 \mathrm{~h}$ at room temperature, whereas EDTA samples were immediately put on ice. Samples were centrifuged at $1100 \times g$ for $10 \mathrm{~min}$; serum and plasma were then separated and frozen at $-20 \mathrm{C}$ and stored at $-80 \mathrm{C}$ until analysis. Folate (27) and vitamin B12 (28) were determined in serum, and tHcy (29), vitamin B6 (30), riboflavin (the nonphosphorylated form) (30), choline, betaine, and dimethylglycine (DMG) (31) were determined in plasma by published methods. Vitamin B6 exists in three main forms in plasma, i.e. pyridoxal 5'-phosphate (PLP), pyridoxal, and pyridoxic acid. PLP is the cofactor form and is measured in the present study (30). The vitamins and metabolites were analyzed in different matrices (serum vs. EDTA plasma) because EDTA interferes with the folate assay (by inhibiting the growth of Lactobacillus casei) and decreases the preanalytical variability for some metabolites, particularly for choline. MTHFR 677 C->T genotyping was performed by using real-time PCR with $5 \mathrm{~V}$ exonuclease (Taqman) probes (32).

\section{Statistics}

Summary measures include medians with 5 th to 95th percentiles. Partial Spearman rank coefficients, adjusted for age, sex, and study center, were used to evaluate associations between variables. The relationship between betaine and tHcy was studied according to folate levels and MTHFR 677 genotype by a Gaussian generalized additive regression model (GAM) (33), as implemented in R (34). The relationships between plasma tHcy and various predictors were also assessed in multiple linear regression models, which were adjusted for age, sex, creatinine, study center, betaine, folate, riboflavin, vitamin B6, vitamin B12, and MTHFR 677 C->T genotype. The vitamin levels were categorized into quartiles for the whole study population. Biochemical variables were represented in the regression models as indicator variables denoting membership to a quartile. The regression coefficient thus estimated the difference in mean tHcy between a reference quartile and the other quartiles. The upper quartile was chosen as reference quartile for betaine, folate, riboflavin, vitamin B6, and vitamin B12, whereas the lower quartile was chosen as the reference for creatinine. Mean tHcy levels across categories for each factor were tested for linear trend. We estimated the strength of the betaine-tHcy relationship in separate groups according to levels of folate (high quartile, Q4; intermediate, Q2 + Q3; low, Q1), MTHFR 677 C-> T genotype, and vitamin B2-6-12 status (high, intermediate, or low). Vitamin B2-6-12 status was based on a vitamin B2-6-12 index score. This index was calculated as the sum of quartile scores $(0-3)$ for riboflavin, vitamin B12, and vitamin B6. An index of $0-2$ was designated low, 3-5 was intermediate, and 6-9 was high vitamin B2-6-12 status. In linear regression analyses with tHcy as the dependent variable, test for trends in the metabolite regression coefficients across the MTHFR $677 \mathrm{C}->$ T genotype (three levels) or folate status (three levels) or the combined B2-B6-B12 status variable (three levels) were obtained from appropriate product terms in the regression model with main effects retained in the model. In these models, we used a linear categorized representation (equally spaced integer scores) of the metabolites. For example, a test for trend in the betaine coefficients across MTHFR genotypes was obtained from the product term in a model with betaine (linear; four levels) + MTHFR (linear; three levels) + betaine*MTHFR + adjustment variables.

SPSS (SPSS Inc., Chicago, IL.) version 11.0 was used for all analyses except the GAM regression analyses, for which we used the statistical package $\mathrm{R}(34)$.

\section{Results \\ Characteristics of the study population}

Plasma and serum samples from 10,601 healthy subjects (age range, 50-64 yr; 50.8\% female) were analyzed. Sex and age distributions were similar within the CC (51.4\%), CT $(40.6 \%)$, and TT $(8.0 \%)$ MTHFR genotypes. Men had higher levels of tHcy, betaine, choline, DMG, and creatinine, but lower levels of vitamin B12, folate, and riboflavin than women $(P<0.001$, data not shown). Subjects with the TT

TABLE 1. Study population characteristics by MTHFR $677 \mathrm{C}->$ T genotype ${ }^{a}$

\begin{tabular}{|c|c|c|c|c|c|}
\hline & $\begin{array}{c}\text { All } \\
(\mathrm{n}=10,601)\end{array}$ & $\begin{array}{c}\mathrm{CC} \\
(\mathrm{n}=5,452)\end{array}$ & $\begin{array}{c}\mathrm{CT} \\
(\mathrm{n}=4,299)\end{array}$ & $\begin{array}{c}\mathrm{TT} \\
(\mathrm{n}=850)\end{array}$ & $P$ for trend \\
\hline tHcy $(\mu \mathrm{mol} /$ liter $)$ & $10.2(6.8-16.4)$ & $9.9(6.7-15.3)$ & $10.4(6.8-16.4)$ & $11.2(7.0-27.0)$ & $<0.001$ \\
\hline Betaine ( $\mu$ mol/liter) & $35.4(19.1-58.3)$ & $35.8(19.3-59.5)$ & $35.3(19.2-57.6)$ & $32.5(17.5-54.6)$ & $<0.001$ \\
\hline Choline ( $\mu \mathrm{mol} /$ liter) & $8.6(5.8-12.9)$ & $8.6(5.8-13.0)$ & $8.6(5.8-12.9)$ & $8.5(5.7-12.2)$ & 0.09 \\
\hline DMG ( $\mu \mathrm{mol} /$ liter $)$ & $3.7(2.4-5.9)$ & $3.8(2.5-6.0)$ & $3.7(2.5-5.9)$ & $3.4(2.2-5.5)$ & $<0.001$ \\
\hline Folate (nmol/liter) & $13.7(6.6-39.4)$ & $14.5(7.3-40.3)$ & $13.4(6.6-39.0)$ & $10.5(5.0-32.1)$ & $<0.001$ \\
\hline Vitamin B12 (pmol/liter) & $307(172-536)$ & $308(175-542)$ & $308(170-532)$ & $300(157-516)$ & 0.19 \\
\hline Vitamin B6 (nmol/liter) & $48.0(18.7-152.4)$ & $47.9(19.1-153.4)$ & $49.0(18.8-153.2)$ & $44.4(15.6-143.1)$ & 0.34 \\
\hline Riboflavin (nmol/liter) & $10.4(4.1-55.9)$ & $10.4(4.1-57.6)$ & $10.4(4.1-54.8)$ & $10.7(3.9-46.5)$ & 0.06 \\
\hline Creatinine ( $\mu \mathrm{mol} /$ liter $)$ & $69(51-92)$ & $69(50-92)$ & $70(51-93)$ & $66(50-89)$ & 0.01 \\
\hline Vitamin $\mathrm{B} 2-6-12$ index & $4.0(1.0-8.0)$ & $4.0(1.0-8.0)$ & $5.0(1.0-8.4)$ & $4.0(1.0-8.0)$ & 0.42 \\
\hline Age (yr) & $55(51-63)$ & $55(51-63)$ & $55(51-63)$ & $55(51-63)$ & 0.11 \\
\hline Males (\%) & 49 & 48 & 50 & 51 & \\
\hline
\end{tabular}

${ }^{a}$ Median (5th to 95 th) percentiles. 
TABLE 2. Partial Spearman correlation coefficients ${ }^{\alpha}$

\begin{tabular}{|c|c|c|c|c|c|c|c|}
\hline & Choline & DMG & Folate & Vitamin B6 & Riboflavin & Vitamin B12 & tHcy \\
\hline Betaine & $0.38^{c}$ & $0.31^{c}$ & $0.19^{c}$ & $0.16^{c}$ & $0.04^{c}$ & $0.07^{c}$ & $-0.22^{c}$ \\
\hline Choline & & $0.33^{c}$ & $0.11^{c}$ & $0.08^{c}$ & $0.05^{c}$ & 0.00 & $-0.06^{c}$ \\
\hline DMG & & & $0.04^{c}$ & $0.04^{c}$ & $0.02^{b}$ & $0.02^{b}$ & $0.02^{b}$ \\
\hline Folate & & & & $0.39^{c}$ & $0.26^{c}$ & $0.16^{c}$ & $-0.44^{c}$ \\
\hline Vitamin B6 & & & & & $0.36^{c}$ & $0.18^{c}$ & $-0.24^{c}$ \\
\hline Riboflavin & & & & & & $0.20^{c}$ & $-0.18^{c}$ \\
\hline Vitamin B12 & & & & & & & $-0.24^{c}$ \\
\hline
\end{tabular}

${ }^{a}$ Ajusted for age, sex, and study center.

${ }^{b} P<0.05$.

${ }^{c} P<0.001$.

genotype had approximately 10\% lower betaine levels, 30\% lower folate levels, and 15\% higher levels of tHcy, compared with CC subjects (Table 1).

\section{Bivariate correlations}

Adjusted Spearman correlation coefficients between concentrations of betaine, choline, DMG, and B-vitamins are shown in Table 2. Betaine, choline, and DMG correlated strongly, but strong positive relations were also found between several B-vitamins, as well as between betaine and B-vitamins.

\section{Betaine determinants}

Determinants of plasma betaine were assessed in a multiple regression model including study center, age, sex, creatinine, choline, folate, riboflavin, vitamins B6 and B12, and MTHFR 677 C->T genotype. Plasma choline (standardized $\beta$-coefficient $=0.37)$, sex $(\beta=0.36)$, and serum folate $(\beta=$ $0.12)$ were the strongest predictors of betaine level $(P<0.001$, adjusted $\left.\mathrm{R}^{2}=0.28\right)$. Subgroup analyses showed that these three variables were also the strongest determinants of plasma betaine in each of the three MTHFR genotypes (data not shown).

\section{Determinants of plasma tHcy}

The relationships between plasma tHcy and concentrations of various B-vitamins and creatinine were assessed in a multiple regression model, which also included age, sex, and study center (Table 3). Betaine, all B-vitamins, and creatinine were significant predictors of $\mathrm{tHcy}$, and the associations with betaine, folate, and riboflavin in particular were strongest in the TT group (Table 3). The estimated difference in mean plasma tHcy between subjects in the lowest compared with the highest quartile of betaine concentrations were $3.2 \mu \mathrm{mol} /$ liter in the TT, $1.2 \mu \mathrm{mol} /$ liter in the CT, and $1.1 \mu \mathrm{mol} /$ liter in the CC groups.

\section{Dose-response relationship between betaine and tHcy}

We constructed dose-response curves for the relationship between plasma betaine and tHcy in strata defined by quartiles of serum folate and by MTHFR $677 \mathrm{C}->$ T genotypes. The curves were obtained using a Gaussian generalized additive model (GAM) (33) and were adjusted for age, sex, creatinine, and study center (Fig. 1). An inverse dose-response relationship between betaine and tHcy was found, which was strong in subjects with the TT genotype and folate in the lowest quartile. A moderate negative betaine-tHcy association was observed in subjects in the lowest folate quartile combined with the CT or CC genotypes, whereas in subgroups with serum folate in quartiles 2-4, the betaine-tHcy relation was weak or essentially absent, irrespective of genotype.

\section{The combined effect of MTHFR status, folate, and other B-vitamins}

To estimate the effect of B-vitamins other than folate, we constructed a B2-6-12 index score, which is the sum of quartile scores (0-3) for concentrations of riboflavin, vitamin B12, and vitamin B6. A B2-6-12 index score was used to avoid small subgroups defined by combinations with each of the $\mathrm{B}$-vitamins. In a multiple regression analyses (adjusting for age, sex, study center, and creatinine), this index score was a stronger predictor of plasma tHcy $(\beta=-0.20)$ than quar-

TABLE 3. Relative strength of plasma tHcy determinants according to MTHFR 677 C->T genotype

\begin{tabular}{|c|c|c|c|c|c|c|c|c|c|}
\hline \multirow{3}{*}{ Determinant } & \multicolumn{8}{|c|}{ Genotype } & \multirow{3}{*}{$P^{a}$} \\
\hline & \multicolumn{2}{|c|}{ All $(\mathrm{n}=10,576)$} & \multicolumn{2}{|c|}{$\mathrm{CC}(\mathrm{n}=5,439)$} & \multicolumn{2}{|c|}{$\mathrm{CT}(\mathrm{n}=4,288)$} & \multicolumn{2}{|c|}{$\mathrm{TT}(\mathrm{n}=849)$} & \\
\hline & $\mu \mathrm{mol} /$ liter & $P^{b}$ & $\mu \mathrm{mol} /$ liter & $P^{b}$ & $\mu \mathrm{mol} /$ liter & $P^{b}$ & $\mu \mathrm{mol} /$ liter & $P^{b}$ & \\
\hline Betaine & $1.46(1.26-1.65)$ & $<0.001$ & $1.11(0.91-1.31)$ & $<0.001$ & $1.17(0.89-1.46)$ & $<0.001$ & $3.21(1.83-4.59)$ & $<0.001$ & $<0.001$ \\
\hline Folate & $3.04(2.84-3.23)$ & $<0.001$ & $2.17(1.96-2.37)$ & $<0.001$ & $2.88(2.60-3.16)$ & $<0.001$ & $4.97(3.58-6.36)$ & $<0.001$ & $<0.001$ \\
\hline Vitamin B12 & $1.42(1.24-1.60)$ & $<0.001$ & $1.14(0.95-1.33)$ & $<0.001$ & $1.46(1.20-1.73)$ & $<0.001$ & $2.78(1.54-4.01)$ & $<0.001$ & $<0.001$ \\
\hline Riboflavin & $0.82(0.63-1.01)$ & $<0.001$ & $0.50(0.30-0.70)$ & $<0.001$ & $0.72(0.44-0.99)$ & $<0.001$ & $3.92(2.57-5.26)$ & $<0.001$ & $<0.001$ \\
\hline Vitamin B6 & $0.55(0.33-0.76)$ & $<0.001$ & $0.42(0.20-0.64)$ & $<0.001$ & $0.36(0.05-0.68)$ & 0.08 & $1.98(0.45-3.51)$ & 0.028 & 0.014 \\
\hline Creatinine & $1.62(1.42-1.83)$ & $<0.001$ & $1.81(1.60-2.03)$ & $<0.001$ & $1.49(1.20-1.79)$ & $<0.001$ & $2.76(1.29-4.23)$ & 0.001 & 0.27 \\
\hline
\end{tabular}

Data are expressed as difference in mean tHcy (95\% confidence interval) between extreme quartiles of each determinant. Data are obtained by multiple regression with tHcy as the dependent variable and all variables in the table as covariates. The model is adjusted for age, sex, and study center.

${ }^{a} P$ for test of trend in the regression coefficient of each determinant across MTHFR 677 C->T genotypes.

${ }^{b} P$ for trend across quartiles of vitamins and metabolites. 


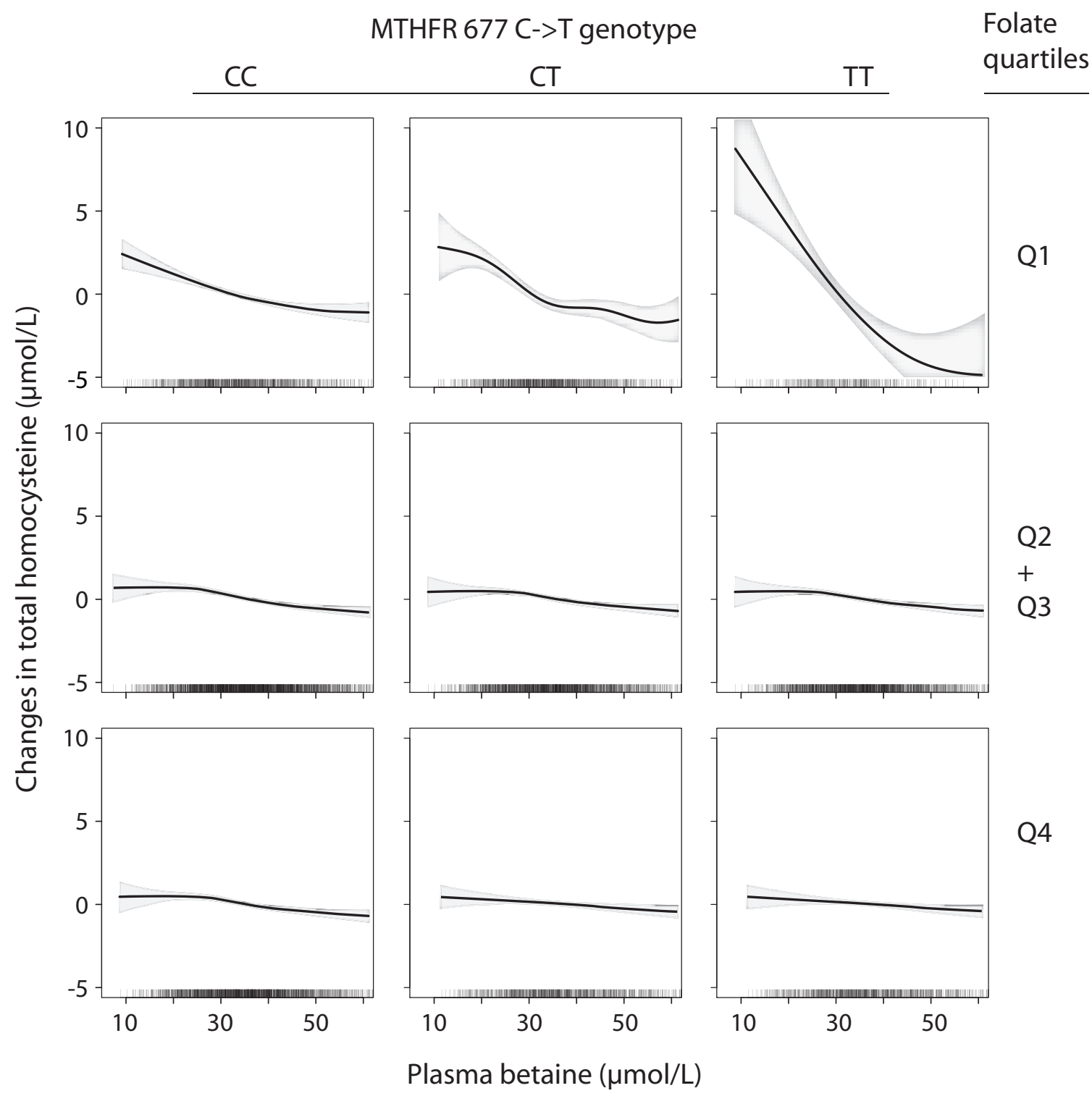

FIG. 1. Dose-response relationship between plasma betaine and tHcy according to MTHFR $677 \mathrm{C}->$ T genotype and folate status. The upper panels show the relationship when serum folate is in the lowest quartile (Q1, <10.1 nmol/liter), the middle panels depict the relationship at intermediate levels of folate (Q2 + Q3, 10.1-20.2 nmol/liter), and the lower panels show the relationship when folate is in the highest quartile (Q4, >20.2 nmol/liter). The solid lines indicate the estimate dose-response curves, and the shaded areas indicate $95 \%$ confidence intervals.

tiles of each B-vitamin or summary scores of each combination of two B-vitamins $(\beta<-0.18)$ (result not shown).

We estimated the simultaneous effect of MTHFR genotype, folate, and other B-vitamins (i.e. B2-6-12 index score) on the betaine-tHcy relationship by multiple linear regression. The model contained these three variables and was additionally adjusted for age, sex, creatinine, and study center. The effect parameter was the difference in mean tHcy between the highest and lowest betaine quartiles (Fig. 2 and Table 4).

In subjects with both low serum folate (Q1) and low vitamin B2-6-12 status, the difference in tHcy (mean, 95\% confidence interval) between those with low (Q1) vs. highplasma betaine (Q4) was $8.79 \mu \mathrm{mol} /$ liter in TT subjects, compared with $4.11 \mu \mathrm{mol} /$ liter in CT and $2.40 \mu \mathrm{mol} /$ liter in CC subjects. In subjects with low serum folate (Q1) and high vitamin B2-6-12 status, these tHcy differences were 4.68, 1.90 , and $0.68 \mu \mathrm{mol} /$ liter in TT, CT, and CC subjects, respectively. The differences in $\mathrm{tHcy}$ between extreme betaine quartiles in the subgroups with the combination of high folate and TT genotype were small and not significantly different from zero, but the estimates were imprecise due to the low subject number (10-63) in these subgroups (Table 4).

\section{Discussion}

This is a cross-sectional study on plasma betaine as a determinant of tHcy in a population of 10,601 subjects. We confirmed previous observations $(11,35)$ that plasma betaine is inversely related to tHcy. A novel observation is that betaine is a particularly strong determinant of tHcy in subjects 
FIG. 2. Betaine as a determinant of tHcy, according to folate status, vitamin B2-6-12 status, and MTHFR $677 \mathrm{C}->$ T genotype. Bars show the difference in mean plasma tHcy ( $\mu \mathrm{mol} /$ /iter) between the lowest plasma betaine quartile $(<28.2 \mu \mathrm{mol} /$ /iter $)$ compared with the highest betaine quartile $(>43.5 \mu \mathrm{mol} /$ liter). Data are obtained by multiple regression analysis adjusted for age, sex, serum creatinine, and study center in 27 subgroups, each defined by MTHFR $677 \mathrm{C}->\mathrm{T}$ genotype (CC, CT, or TT), level of folate (low, Q1; intermediate, Q2 + 3; or high, Q4) and vitamin B2-6-12 status (low, intermediate, or high).

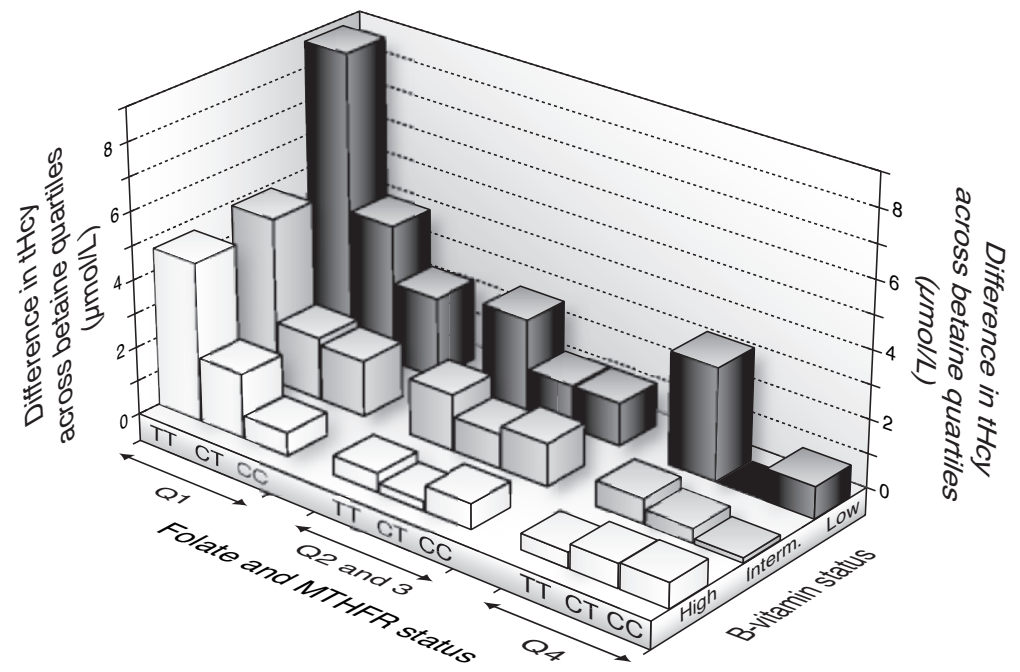

with the MTHFR 677 TT genotype in combination with low levels of folate and other B-vitamins.

\section{Study design}

The large study population allowed precise estimates of betaine-tHcy associations in the entire population, as well as in subgroups. For example, of the 850 subjects with the TT genotype, 397 had low serum folate and 144 individuals (1.4\% of the study population) had both low serum folate and low vitamin B2-6-12 status. Furthermore, age and ethnicity can influence tHcy levels, and the homogeneity of the study population reduces confounding from these variables.

\section{Concentrations of tHcy, betaine, and folate}

The median concentration of plasma betaine was 35.4 $\mu \mathrm{mol} /$ liter, which is in agreement with previous reports from studies of healthy individuals $(11,31,36)$. Median tHcy was approximately $15 \%$ higher and folate was 30\% lower in subjects with the TT genotype, compared with the CC genotype, as has consistently been demonstrated in other studies $(24,37)$. Betaine concentrations were related to MTHFR genotype and showed a small decrease according to the number of $\mathrm{T}$ alleles. This may reflect that betaine and 5-MTHF are fungible sources of methyl groups (38), and impaired formation of 5-MTHF in subjects with the MTHFR 677 TT genotype may lead to increased betaine consumption through the BHMT pathway.

\section{Folate and other B-vitamins}

B-vitamins, including folate, vitamin B12, riboflavin, and vitamin B6, serve as cofactors in several pathways of onecarbon metabolism (18). In addition, the metabolic functions of these B-vitamins are interconnected, because some enzymes involved in their activation require another B-vitamin as a cofactor (39). Such a functional network, and the fact that intakes of different B-vitamins correlate (40), may explain the positive relationships between the concentrations of B-vitamins reported in the present study (Table 2) and by others (40). This is the background for constructing a composite variable for the concentrations of riboflavin, vitamin $\mathrm{B} 6$ and vitamin B12, i.e. the vitamin B2-6-12 index.

We observed an inverse relationship between plasma betaine and tHcy, which extended across the whole concentration range of betaine (Fig. 1). The tHcy difference between subjects in extreme betaine quartiles was strongest at low serum folate and was particularly pronounced in the subgroup with a low vitamin B2-6-12 status (Fig. 2 and Table 4). These observations agree with the idea that Hcy is directed to the BHMT pathway under conditions of impaired folatedependent remethylation (41). Impaired remethylation may occur if methionine synthase (MS) function is inhibited directly, by insufficient dietary supply of vitamin B12 or folate, or indirectly, by low MTHFR activity. Conceivably, high concentrations of the cofactors (methylcobalamin for MS or flavin adenine dinucleotide for MTHFR) may boost low enzyme activities caused by insufficient concentrations of substrates (5-MTHF and 5,10-methylenetetrahydrofolate, respectively) and vice versa. Such cooperative mechanisms may explain the interaction between folate and other B-vitamins observed in the present study.

\section{MTHFR 677 C->T genotype}

The strong association between tHcy and betaine in subjects with the combination of low B-vitamin status and the MTHFR TT genotype may reflect up-regulation of the betaine-dependent Hcy remethylation under conditions of impaired activity of 5-MTHF-dependent MS. 5-MTHF formation is inhibited when MTHFR activity is low (20), and in vitro studies on recombinant human MTHFR show that the variant associated with the $677 \mathrm{C}->\mathrm{T}$ transition has a propensity to lose its cofactor, flavin adenine dinucleotide, particularly at low folate (42). This might explain why riboflavin, folate, and MTHFR genotype are cooperative determinants of the tHcy-betaine relationship.

\section{Conclusion}

Plasma betaine is a strong determinant of plasma tHcy, predominantly in subjects with low levels of folate and other 


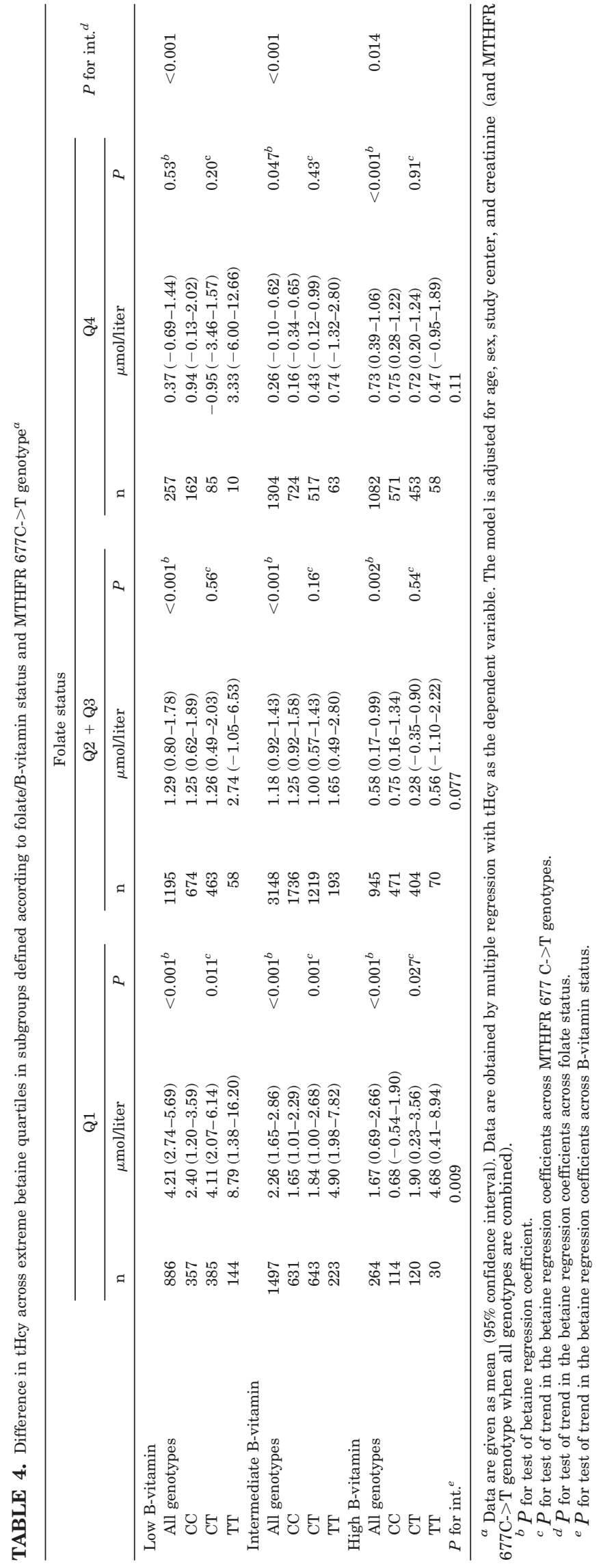

B-vitamins and the MTHFR 677TT genotype. This observation strongly supports the idea that betaine is an important source of one-carbon units, in particular when folate status is compromised, whether caused by inadequate nutrition or genetic factors. This points to the role of betaine as a onecarbon source but also highlights the importance of betaine measurement in studies on folate and Hcy status in relation to chronic diseases.

\section{Acknowledgments}

Received July 10, 2006. Accepted January 25, 2007.

Address all correspondence and requests for reprints to: Per Magne Ueland, Section for Pharmacology, Institute of Medicine, Armauer Hanssens hus, University of Bergen, 5021 Bergen, Norway. E-mail: per.ueland@ikb.uib.no.

This work was supported by the Foundation to Promote Research into Functional Vitamin B12 Deficiency.

Disclosure Summary: P.I.H., S.H., S.E.V., T.G., and J.S. have nothing to declare. P.M.U. reports having received consulting fees from $\mathrm{Ny}-$ comed and is a member of the steering board of the nonprofit Foundation to Promote Research into Functional Vitamin B12 Deficiency. A PTC application (62924 [52365]) for a patent entitled "Determination of folate in fresh and stored serum or plasma as paraaminobenzoylglutamate" was filed on March 3, 2005; P.M.U. is listed as one of the inventors.

\section{References}

1. De Bree A, Verschuren WMM, Kromhout D, Kluijtmans LAJ, Blom HJ 2002 Homocysteine determinants and the evidence to what extent homocysteine determines the risk of coronary heart disease. Pharmacol Rev 54:599-618

2. Carmel R, Jacobsen D 2001 Homocysteine in health and disease. Cambridge, UK: Cambridge University Press

3. Refsum H, Ueland PM, Nygard O, Vollset SE 1998 Homocysteine and cardiovascular disease. Annu Rev Med 49:31-62

4. Wilcken DE, Wilcken B 1997 The natural history of vascular disease in homocystinuria and the effects of treatment. J Inherit Metab Dis 20:295-300

5. Brouwer IA, Verhoef P, Urgert R 2000 Betaine supplementation and plasma homocysteine in healthy volunteers. Arch Intern Med 160:2546-2547

6. Schwab U, Torronen A, Toppinen L, Alfthan G, Saarinen M, Aro A, Uusitupa M 2002 Betaine supplementation decreases plasma homocysteine concentrations but does not affect body weight, body composition, or resting energy expenditure in human subjects. Am J Clin Nutr 76:961-967

7. Steenge GR, Verhoef P, Katan MB 2003 Betaine supplementation lowers plasma homocysteine in healthy men and women. J Nutr 133:1291-1295

8. Olthof MR, Van Vliet T, Boelsma E, Verhoef P 2003 Low dose betaine supplementation leads to immediate and long term lowering of plasma homocysteine in healthy men and women. J Nutr 133:4135-4138

9. Alfthan G, Tapani K, Nissinen K, Saarela J, Aro A 2004 The effect of low doses of betaine on plasma homocysteine in healthy volunteers. Br J Nutr 92:665-669

10. Schwab U, Torronen A, Meririnne E, Saarinen M, Alfthan G, Aro A, Uusitupa M 2006 Orally administered betaine has an acute and dose-dependent effect on serum betaine and plasma homocysteine concentrations in healthy humans. J Nutr 136:34-38

11. Holm PI, Ueland PM, Vollset SE, Midttun O, Blom HJ, Keijzer MB, den Heijer M 2005 Betaine and folate status as cooperative determinants of plasma homocysteine in humans. Arterioscler Thromb Vasc Biol 25:379-385

12. Ueland PM, Holm PI, Hustad S 2005 Betaine: a key modulator of one-carbon metabolism and homocysteine status. Clin Chem Lab Med 43:1069-1075

13. Garrow T 2001 Betaine-dependent remethylation. In: Carmel R, Jacobsen D, eds. Homocysteine in health and disease. Cambridge, UK: Cambridge University Press

14. McKinley MC, McNulty H, McPartlin J, Strain JJ, Pentieva K, Ward M, Weir DG, Scott JM 2001 Low-dose vitamin B-6 effectively lowers fasting plasma homocysteine in healthy elderly persons who are folate and riboflavin replete. Am J Clin Nutr 73:759-764

15. Ubbink JB, van der Merwe A, Delport R, Allen RH, Stabler SP, Riezler R, Vermaak WJ 1996 The effect of a subnormal vitamin B-6 status on homocysteine metabolism. J Clin Invest 98:177-184

16. Selhub J, Miller JW 1992 The pathogenesis of homocysteinemia: interruption of the coordinate regulation by S-adenosylmethionine of the remethylation and transsulfuration of homocysteine. Am J Clin Nutr 55:131-138

17. Hustad S, Ueland PM, Vollset SE, Zhang Y, Bjorke-Monsen AL, Schneede J 2000 Riboflavin as a determinant of plasma total homocysteine: effect modification by the methylenetetrahydrofolate reductase C677T polymorphism. Clin Chem 46:1065-1071 
18. Finkelstein JD 1990 Methionine metabolism in mammals. J Nutr Biochem $1: 228-237$

19. Pfeiffer CM, Fazili Z, McCoy L, Zhang M, Gunter EW 2004 Determination of folate vitamers in human serum by stable-isotope-dilution tandem mass spectrometry and comparison with radioassay and microbiologic assay. Clin Chem 50:423-432

20. Bailey LB, Gregory 3rd JF 1999 Polymorphisms of methylenetetrahydrofolate reductase and other enzymes: metabolic significance, risks and impact on folate requirement. J Nutr 129:919-922

21. Botto LD, Yang Q 2000 5,10-Methylenetetrahydrofolate reductase gene variants and congenital anomalies: a HuGE review. Am J Epidemiol 151:862-877

22. Kang SS, Wong PW, Susmano A, Sora J, Norusis M, Ruggie N 1991 Thermolabile methylenetetrahydrofolate reductase: an inherited risk factor for coronary artery disease. Am J Hum Genet 48:536-545

23. Frosst $P$, Blom HJ, Milos R, Goyette P, Sheppard CA, Matthews RG, Boers GJ, den Heijer M, Kluijtmans LA, van den Heuvel LP 1995 A candidate genetic risk factor for vascular disease: a common mutation in methylenetetrahydrofolate reductase. Nat Genet 10:111-113

24. Jacques PF, Bostom AG, Williams RR, Ellison RC, Eckfeldt JH, Rosenberg IH, Selhub J, Rozen R 1996 Relation between folate status, a common mutation in methylenetetrahydrofolate reductase, and plasma homocysteine concentrations. Circulation 93:7-9

25. Bretthauer M, Gondal G, Larsen K, Carlsen E, Eide TJ, Grotmol T, Skovlund E, Tveit KM, Vatn MH, Hoff G 2002 Design, organization and management of a controlled population screening study for detection of colorectal neoplasia: attendance rates in the NORCCAP study (Norwegian Colorectal Cancer Prevention). Scand J Gastroenterol 37:568-573

26. Gondal G, Grotmol T, Hofstad B, Bretthauer M, Eide TJ, Hoff G 2003 The Norwegian Colorectal Cancer Prevention (NORCCAP) screening study: baseline findings and implementations for clinical work-up in age groups 50-64 years. Scand J Gastroenterol 38:635-642

27. O'Broin S, Kelleher B 1992 Microbiological assay on microtitre plates of folate in serum and red cells. J Clin Pathol 45:344-347

28. Kelleher BP, Broin SD 1991 Microbiological assay for vitamin B12 performed in 96-well microtitre plates. J Clin Pathol 44:592-595

29. Windelberg A, Arseth O, Kvalheim G, Ueland PM 2005 Automated assay for the determination of methylmalonic acid, total homocysteine, and related amino acids in human serum or plasma by means of methylchloroformate derivatization and gas chromatography-mass spectrometry. Clin Chem 51: 2103-2109
30. Midttun O, Hustad S, Solheim E, Schneede J, Ueland PM 2005 Multianalyte quantification of vitamin B6 and B2 species in the nanomolar range in human plasma by liquid chromatography-tandem mass spectrometry. Clin Chem 51:1206-1216

31. Holm PI, Ueland PM, Kvalheim G, Lien EA 2003 Determination of choline, betaine, and dimethylglycine in plasma by a high-throughput method based on normal-phase chromatography-tandem mass spectrometry. Clin Chem 49: 286-294

32. Ulvik A, Ueland PM 2001 Single nucleotide polymorphism (SNP) genotyping in unprocessed whole blood and serum by real-time PCR: application to SNPS affecting homocysteine and folate metabolism. Clin Chem 47:2050-2053

33. Hastie T, Tibshirani R 1986 Generalized additive models. Stat Sci 297-310

34. R Development Core Team $2006 \mathrm{R}$ : a language and environment for statistical computing. Vienna: R Foundation for Statistical Computing

35. Melse-Boonstra A, Holm PI, Ueland PM, Olthof M, Clarke R, Verhoef P 2005 Betaine concentration as a determinant of fasting total homocysteine concentrations and the effect of folic acid supplementation on betaine concentrations. Am J Clin Nutr 81:1378-1382

36. Lever M, Sizeland PC, Bason LM, Hayman CM, Chambers ST 1994 Glycine betaine and proline betaine in human blood and urine. Biochim Biophys Acta 1200:259-264

37. Brattstrom L, Wilcken DE, Ohrvik J, Brudin L 1998 Common methylenetetrahydrofolate reductase gene mutation leads to hyperhomocysteinemia but not to vascular disease: the result of a meta-analysis. Circulation 98:2520-2526

38. Niculescu MD, Zeisel SH 2002 Diet, methyl donors and DNA methylation: interactions between dietary folate, methionine and choline. J Nutr 132:2333S$2335 \mathrm{~S}$

39. Hustad S, Schneede J, Ueland PM 2005 Riboflavin and methylenetetrahydrofolate reductase. In: Ueland PM, Rozen R, eds. MTHFR polymorphisms and disease. Georgetown, Texas: Landes Bioscience/Eurekah; 71-77

40. Shimakawa T, Nieto FJ, Malinow MR, Chambless LE, Schreiner PJ, Szklo M 1997 Vitamin intake: a possible determinant of plasma homocyst(e)ine among middle-aged adults. Ann Epidemiol 7:285-293

41. Finkelstein JD, Martin JJ, Harris BJ 1988 Methionine metabolism in mammals. The methionine-sparing effect of cystine. J Biol Chem 263:11750-11754

42. Yamada K, Chen Z, Rozen R, Matthews RG 2001 Effects of common polymorphisms on the properties of recombinant human methylenetetrahydrofolate reductase. Proc Natl Acad Sci USA 98:14853-14858

JCEM is published monthly by The Endocrine Society (http://www.endo-society.org), the foremost professional society serving the endocrine community. 